\title{
GENETIC POLYMORPHISMS OF IL-17A IN ASSOCIATION WITH THE RISK OF PULMONARY TUBERCULOSIS IN IRAQI PATIENTS
}

\author{
NADA YAS AMEEN ${ }^{1}$, MOHAMMED QAIS ABED ${ }^{1 *}$, NAWAL MOHAMMED UTBA ${ }^{2}$, AHMED ASMAR MANKHI ${ }^{3}$ \\ ${ }^{1}$ Department of Biololgy, College of Science, University of Anbar, Iraq. ${ }^{2}$ Department of Biololgy, College of Science, University of \\ Baghdad, Iraq. ${ }^{3}$ Department of National Center for Thoracic and Respiratory Diseases, Ministry of Public Health, Baghdad, Iraq. Email: \\ drmohammedqais1975@gmail.com
}

Received: 19 March 2018, Revised and Accepted: 30 June 2018

ABSTRACT

Objectives: Tuberculosis (TB) is an infectious disease that usually affects the lungs caused by Mycobacterium tuberculosis, TB is the second biggest killer, globally. The aim of this study was to examine the association between IL-17A rs2275913 SNP and pulmonary TB susceptibility in Iraqi population.

Methods: From January 2017 to April 2017, 80 pulmonary TB patients were selected as the case group, another 40 healthy control were enrolled as the control group. The genotype frequencies of IL-17A rs2275913 was detected using amplification refractory mutation system.

Results: The results of IL-17A serum level demonstrated that there were significant differences ( $<<0.05)$ between patients groups. The result showed that A allele have a higher frequency ( $55 \%$ vs. $50 \%$ ) in TB patients than the control sample with OR value of 1.22 and EF value 0.1 and G have lower frequency ( $45 \%$ vs. $50 \%$ ) in TB patients than control sample with OR value of 0.82 with PF value of 0.09 , but this difference was not statistically significant $(\mathrm{p}>0.05)$

Conclusion: There were no significant associations between IL-17A rs2275913 polymorphism and risk of TB in Iraqi population.

Keywords: Tuberculosis, Cytokine, IL-17A, Polymorphism, Association, Amplification refractory mutation system.

(C) 2018 The Authors. Published by Innovare Academic Sciences Pvt Ltd. This is an open access article under the CC BY license (http://creativecommons. org/licenses/by/4. 0/) DOI: http://dx.doi.org/10.22159/ajpcr.2018.v11i10.26008

\section{INTRODUCTION}

Tuberculosis (TB) is an infectious disease in which the immune system plays an important role [1]. TB is a deadly infectious disease in the world, although the incidence of TB has declined in recent years, it is out of control in some parts of the world [2].

Moreover, this is a big problem around the world [3]. In addition, it is still responsible for a wide range of deaths worldwide [4]. Even though DOTS procedure can decrease cost, accomplish powerful cure, and save life of TB patients, still patients need to spend for other investigations and other drugs [5]. The cytokines represent an important part of the immune system that helps to differentiate TB infection from the non-infected state [6]. There is a major role for cytokines in the development or progression of $\mathrm{TB}$, so be responsible for the functions of the SNPs in the impact of TB [7]. Cytokines play an important role in the immune response to TB [8]. Implications of genetic polymorphisms single-nucleotide polymorphisms (SNPs) located on promoter regions or coding regions of cytokine genes as host factors influencing susceptibility to TB have been investigated, and cytokine production levels may change in TB patients due to some mutations in these genes that affect the locations of transcription factor regions and then affect the activation of the transcription [9]. Until now, many gene polymorphisms have been suggested as being related with susceptibility to TB [10]. IL-17A is linked to the development of autoimmunity, inflammation, and tumors, which plays a defensive role against bacterial and fungal infections in host defenses [11,12]. IL-17A is a chief driver of multiple inflammatory and immune disorders [13]. Overabundance production during chronic inflammation has been related with many inflammatory and autoimmune disorders $[11,14]$. Genetic variations in and IL-17A have been generally connected to various diseases. Associations between susceptibility and resistance to different infections and SNPs in IL17A have been found [14]. The gene polymorphisms of IL-17A is associated with the susceptibility to various inflammatory diseases [15]. For these reasons, IL-17A is the most sensitive to TB disease [16]. And have an important role in host defence against MTB [17]. Some SNPs are considered to have normal gene variations that do not cause any disease but may affect the function of gene products [7].

\section{MATERIALS AND METHODS}

\section{Method}

A total of 80 patients with active TB were diagnosed at National Reference Laboratory of TB, Baghdad, from January 2017 to April 2017 for diagnosis and treatment. Patients were divided into three groups, multidrug resistant (MDR), recently diagnosed (RD), and old cases (OC) as well as forty apparently healthy people were selected as the control group. All patients and control group ages ranged between 12 and 76 years old.

\section{Blood sample}

Five milliliters of venous blood samples were collected from both patients and healthy human, and it was divided into two tubes ( $2 \mathrm{ml}$ ) and $(3 \mathrm{ml})$. The first whole-blood sample was dispense in tube containing ethylenediaminetetracetic acid into an EDTA-tube, this blood was mixed gently and then stored placed in the freezer at $-20^{\circ} \mathrm{C}$ until further processing for DNA extraction. The second tube was serum isolated by centrifuge at (3000 rpm) for $10 \mathrm{~min}$.

\section{IL-17A ELISA}

Levels of IL-17A from TB patients and healthy controls were measured using a commercial ELISA kit (Human IL-17A, Biosource, USA).

DNA extraction, SNP primers design, and genotyping Genomic DNA was extracted from whole-blood samples using Genomic DNA Extraction Kit (Promega, USA) according to the manufacturer's instructions. DNA purity and final concentrations were determined using 
Nanodrop Software (Bioneer/korea) in at (260/280 nm). Amplification refractory mutation system-polymerase chain reaction was used for the rs2275913 SNP genotyping. Primer sequences were designed using allele-specific primers of SNPs online tool from NCBI-GenBank database and BatchPrimer design online. The sequences of the primers used are: Allele G-specific forward 5'-GAGGTCATAGAAGAATCTCAC -3', Allele A-specific forward 5'-GAGGTCATAGAAGAATCTCTT-3', and Common Reverse 5'-TGAGTAGTTTCCGGAATTGT-3'. The primers used in this study were obtained from Macrogen, Korea. The conditions included initial denaturation $\left(95^{\circ} \mathrm{C}\right.$ for $\left.4 \mathrm{~min}\right)$ following a 25 time cycles of denaturation at $95^{\circ} \mathrm{C}$ for $30 \mathrm{~s}$, annealing at $53^{\circ} \mathrm{C}$ for $30 \mathrm{~s}$, and extension at $72^{\circ} \mathrm{C}$ for $30 \mathrm{~s}$ each cycle and the final extension at $72^{\circ} \mathrm{C}$ for $7 \mathrm{~min}$. rs2275913 genotypes were assessed from the presence/absence of PCR amplicon (320bp), corresponding to the specific allele (A/G) on $2 \%$ agarose gel.

\section{Statistical analysis}

All statistical analysis was performed using the Statistical Package for the Social Sciences (SPSS) program version 17 for Windows (SPSS INC., Chicago IL, USA). Results were expressed as mean \pm standard deviation (SD). Comparisons between two groups were performed using t-test for categorical data. $\mathrm{p}<0.05$ were considered to indicate statistical significance.

\section{RESULTS}

\section{IL-17A serum level}

The results of IL-17A serum level demonstrated that there were significantly decreased $(\mathrm{p}<0.001)$ in MDR group than control, while $\mathrm{RD}$ and $\mathrm{OC}$ groups demonstrated insignificantly variation than control. Among patients group, there were significant differences $(p<0.05)$ in the levels of IL-17A between MDR and RD, MDR and OC, and RD with $\mathrm{OC}$ as shown in Fig. 1.

\section{DNA isolation}

The purity of extracted DNA ranged between 0.96 and 1.98 with concentration means \pm SD was $95.6 \pm 45.9 \mathrm{ng}$.

\section{Genotypic and allelic frequencies of the IL-17A rs2275913 SNP in} TB and control populations

The genotyping of IL-17A rs2275913 gene polymorphism was determined in both TB patients and controls using two sets of allelespecific primers. The PCR product size was $320 \mathrm{bp}$. The positive amplification of both PCR reactions exhibited a GG genotype, while positive amplification in only the first PCR reaction exhibited a GA genotype and finally, the positive amplification in the second reaction only showed an AA genotype of IL-17A rs2275913 gene polymorphism as shown in Figs. 2 and 3.

Testing for Hardy-Weinberg (H-W) equilibrium revealed that MDR, RD, OC patients and control groups showed a significant $(\mathrm{p} \leq 0.001)$ variation in the distribution of IL-17A genotypes at a position rs2275913. Such differences were observed due to differences between the observed and expected frequency of GG, GA, and AA genotypes; the homozygote GG genotype was observed with $0 \%$ frequency, while the expected frequency was $20.25 \%$ in all patient groups. In the control group, the observed frequency was $2.5 \%$, while the expected frequency was $25 \%$. The heterozygote GA observed with $90 \%$ frequency, while the expected frequency was $49.5 \%$ in all the patient groups. In the control group, the observed frequency was $95 \%$, while the expected frequency was $50 \%$. The AA homozygote genotype was observed with $10 \%$ frequency, while the expected frequency was $30.25 \%$ in all patient groups and in control group, the observed frequency was $2.5 \%$, while the expected frequency was $25 \%$ (Table 1). None of the genotypes (GG, GA, and AA) frequency or alleles of IL-17A at a position rs2275913 showed significant differences between TB patient groups than control group (Table 2).

IL-17A serum levels from TB and control carrying the rs2275913 SNP variants

The impact of interleukins genotypes on the production of investigated interleukins in TB patients and control groups were determined and

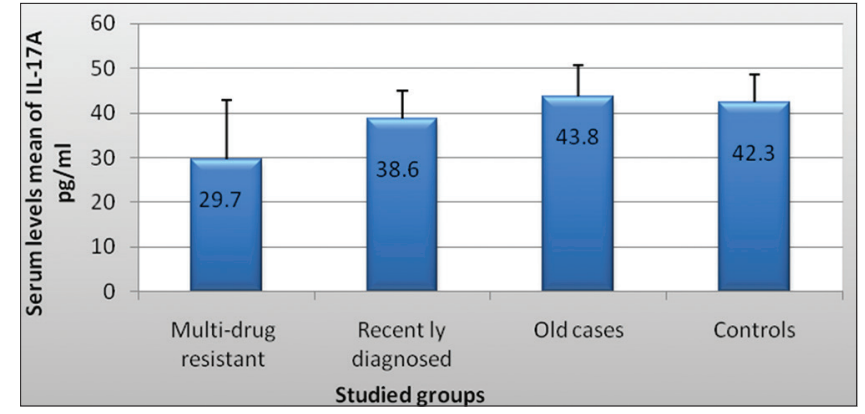

Fig. 1: Serum level of IL-17A in tuberculosis patients and controls.

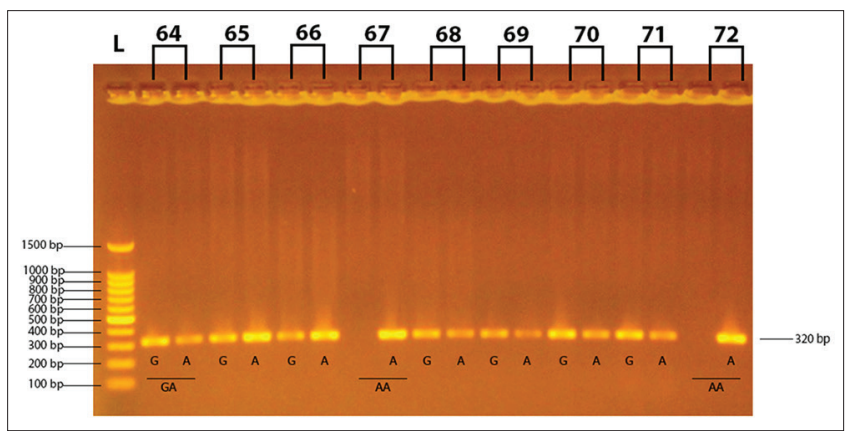

Fig. 2: Amplification refractory mutation system-polymerase chain reaction of IL-17A rs2275913 gene polymorphism. Sample No. 64, 65, 66, 68, 69, 70, and 71 show GA genotype while Sample No.67 and 72 show AA genotype. L: Ladder DNA

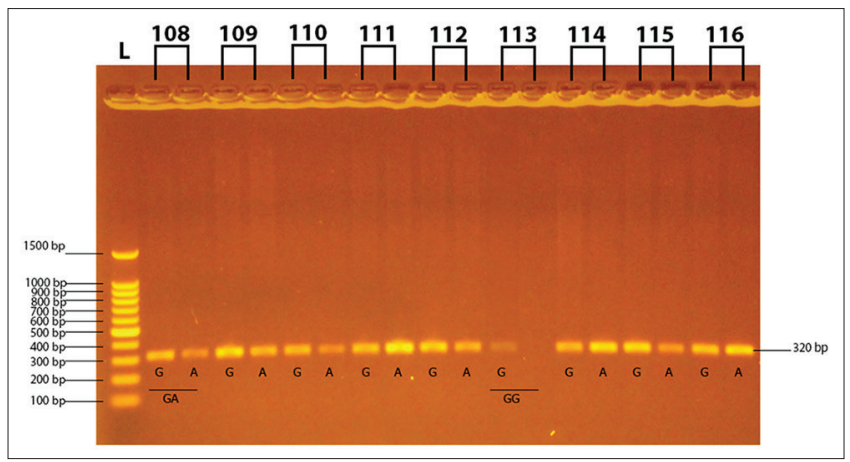

Fig. 3: Amplification refractory mutation system-polymerase chain reaction of IL-17A rs2275913 gene polymorphism. Sample No. 108, 109, 110, 111, 112, 114, 115, and 116 show GA genotype while Sample No.113 shows GG genotype. L: Ladder DNA

distributed according to their serum level in the three genotypes for further understanding of interleukins gene polymorphisms role in TB infection. There were no significant differences in serum levels of IL-17A between TB patients and controls with different genotypes (Table 3).

\section{DISCUSSION}

The present study showed a significant difference in serum level of IL-17A in TB patients. Such finding is in agreement with Ocejo-Vinyals etal. [18] in which similar results were obtained that showed a significant difference in serum level of IL-17A in TB patients. Another studies have shown that the serum level of IL-17A does not differ between cases and controls [19]. Serum of IL-17A level may be adjunctive biomarkers for differential diagnosis of active TB [20]. The lower serum IL-17A level of 
Table 1: Observed and expected number with the percentage frequencies and Hardy-Weinberg (H-W) equilibrium of IL-17A rs2275913 genotypes and alleles in TB patients and control groups

\begin{tabular}{|c|c|c|c|c|c|c|}
\hline \multirow[t]{2}{*}{ Studied groups } & \multicolumn{5}{|c|}{ IL-17A rs2275913 genotypes or allele } & \multirow[t]{2}{*}{ H-W P $\leq$} \\
\hline & GG & GA & AA & G & $\mathbf{A}$ & \\
\hline \multicolumn{7}{|c|}{ TB patient groups (N: 80) } \\
\hline \multicolumn{7}{|c|}{ MDR (N: 40) n (\%) } \\
\hline Observed & $0(0)$ & $36(90)$ & $4(10)$ & $36(45)$ & $44(55)$ & 0.001 \\
\hline Expected & $8.1(20.25)$ & $19.8(49.5)$ & $12.1(30.25)$ & Not estimated & & \\
\hline \multicolumn{7}{|l|}{$\mathrm{RD}(\mathrm{N}: 20)$ n $(\%)$} \\
\hline Expected & $4.05(20.25)$ & $9.9(49.5)$ & $6.05(30.25)$ & Not estimated & & \\
\hline \multicolumn{7}{|c|}{ OC (N: 20$)$ n (\%) } \\
\hline Observed & $0(0)$ & $18(90)$ & $2(10)$ & $18(45)$ & $22(55)$ & 0.001 \\
\hline Expected & $4.05(20.25)$ & $9.9(49.5)$ & $6.05(30.25)$ & Not estimated & & \\
\hline \multicolumn{7}{|c|}{ Control Group (N: 40) } \\
\hline \multicolumn{7}{|c|}{$\mathrm{n}(\%)$} \\
\hline Expected & $1(2.5)$ & $38(95)$ & $1(2.5)$ & $40(50)$ & $40(50)$ & 0.001 \\
\hline Observed & $10(25)$ & $20(50)$ & $10(25)$ & Not estimated & & \\
\hline
\end{tabular}

Table 2: Statistical evaluations of association between IL-17A rs2275913 genotypes or allele in TB patients and control groups

\begin{tabular}{|c|c|c|c|c|c|c|}
\hline $\begin{array}{l}\text { IL-17A rs2275913 } \\
\text { genotypes or allele }\end{array}$ & $\begin{array}{l}\text { Patients (N: 80) } \\
\text { n (\%) }\end{array}$ & $\begin{array}{l}\text { Controls (N: 40) } \\
\text { n (\%) }\end{array}$ & OR & $\begin{array}{l}\text { Etiological or Preventive } \\
\text { Fraction }\end{array}$ & $\begin{array}{l}\text { Fisher's Exact } \\
\text { Probability }\end{array}$ & $95 \%$ CI \\
\hline Genotypes & MDR (N: 40) & & & & & \\
\hline GG & $0(0)$ & $1(2.5)$ & - & - & - & - \\
\hline GA & $36(90)$ & 38 (95) & 0.47 & 0.5 & 0.675 & $0.08-2.69$ \\
\hline AA & $4(10)$ & $1(2.5)$ & 4.33 & 0.07 & 0.359 & $0.01-7.90$ \\
\hline \multicolumn{7}{|l|}{ Alleles } \\
\hline G & $36(45)$ & $40(50)$ & 0.82 & 0.09 & 0.635 & $0.44-1.52$ \\
\hline A & $44(55)$ & $40(50)$ & 1.22 & 0.1 & 0.635 & $0.66-2.27$ \\
\hline Genotypes & $\mathrm{RD}(\mathrm{N}: 20)$ & & & & & \\
\hline GG & $0(0)$ & $1(2.5)$ & - & - & - & - \\
\hline GA & $18(90)$ & 38 (95) & 0.47 & 0.5 & 0.595 & $0.06-3.50$ \\
\hline $\mathrm{AA}$ & $2(10)$ & $1(2.5)$ & 4.33 & 0.07 & 0.225 & $0.38-48.86$ \\
\hline \multicolumn{7}{|l|}{ Alleles } \\
\hline G & $18(45)$ & $40(50)$ & 0.82 & 0.09 & 0.699 & $0.39-1.74$ \\
\hline A & $22(55)$ & $40(50)$ & 1.22 & 0.1 & 0.699 & $0.58-2.60$ \\
\hline Genotypes & OC (N: 20$)$ & & & & & \\
\hline GG & $0(0)$ & $1(2.5)$ & - & - & - & - \\
\hline GA & $18(90)$ & 38 (95) & 0.47 & 0.5 & 0.595 & $0.06-3.50$ \\
\hline $\mathrm{AA}$ & $2(10)$ & $1(2.5)$ & 4.33 & 0.07 & 0.225 & $0.38-48.86$ \\
\hline \multicolumn{7}{|l|}{ Alleles } \\
\hline G & $18(45)$ & $40(50)$ & 0.82 & 0.09 & 0.699 & $0.39-1.74$ \\
\hline A & $22(55)$ & $40(50)$ & 1.22 & 0.1 & 0.699 & $0.58-2.60$ \\
\hline
\end{tabular}

MDR: Multidrug resistant, RD: Recently diagnosed, OC: Old cases, OR: Odd ratio, CI: Confidence intervals

MDR may reflect a weaker Th1 immune response against mycobacterial infections [21] which is important in stimulating an optimal immune response to Th1. This decrease in MDR-TB is due to non-compliance of the patients with commitment to treatment. Furthermore, the rapid non-detection of MDR-TB, which is necessary to begin developing an appropriate treatment manner to control MDR-TB [22]. Perhaps, due to the long path of processing with the second-line anti-inflammatory drugs (ATDs) have higher side effects and cost, Shaji et al. and Butov et al. $[23,24]$ assume that Th1-lymphocyte activity decrease in this group of patients. In the present study, decrease level of IL-17A in MDR may be due to stopping the treat before the end of the prescribed period or leaving some doses and irregularity in the treatment allows the bacteria to become resistant to antibiotics, making the disease more serious and difficult to treat, affecting the function of the immune system, and thus reduce the level of IL-17A in MDR-TB patient. In addition, MDR-TB patients infected with resistant strains to TB drugs that may be block the action of IL-17A. Basile et al. [25] reported that IL-17A has an important and essential role in MDR-TB patients and the genetic background of the infecting Mycobacterium tuberculosis strain on the Th17 response. Hence, we can use IL-17A as a marker for early detection of MDR-TB patients.
TB and control population in the present study did not agree with the $\mathrm{H}-\mathrm{W}$ equilibrium and have ethnic differences. In other studies, there were showed $\mathrm{H}-\mathrm{W}$ equilibrium in PTB and control population for rs2275913 SNP in Polish and Argentina population [26, 27]. Du et al. and Shi et al. $[28,29]$ showed that the IL-17A rs2275913 was found to be in line with H-W equilibrium in controls in a Chinese population. The result showed that A allele have a higher frequency (55\% vs. 50\%) in TB patients than control sample with odd ratio (OR) value of 1.22 and EF value 0.1 and G have a lower frequency ( $45 \%$ vs. $50 \%$ ) in TB patients than control sample with OR value of 0.82 with PF value of 0.09 . These results are in agreement with those obtained by Du et al. and Shi et al. $[28,29]$ in Chinese population which shows that the percentage of A allele was higher among TB patients compared to control, while the $\mathrm{G}$ allele showed a higher percentage of control. These results do not agree with a study by Ocejo-Vinyals et al. and Wang et al. $[18,30]$ who demonstrated that frequency A allele associated with the risk of TB in Chinese and northern Spain population, respectively. A study by Shi and Zhang [29] showed that AA genotype is associated with an increased susceptibility to TB risk. Bulat-Kardum et al. [17] showed that the frequency of allele A $(32.19 \%)$ is higher than the frequency of allele G (67.81\%) in Chinese population. Mansouri et al. [31] found 
Table 3: Serum level of IL-17A in TB patients and controls distributed by IL-17A rs2257913 genotypes

\begin{tabular}{llll}
\hline \multirow{2}{*}{ Groups } & \multicolumn{4}{l}{ IL-17A serum level mean \pm SD $\mathbf{~ p g} / \mathbf{m l}$} \\
\cline { 2 - 4 } & GG & GA & AA \\
\hline Patients (N: 80) & - & & \\
MDR (N: 40) & - & $29.64 \pm 13.6^{\mathrm{A}}$ & $30.57 \pm 13.0^{\mathrm{A}}$ \\
RD (N: 20) & - & $38.1 \pm 6.6^{\mathrm{A}}$ & $42.9 \pm 0.98^{\mathrm{A}}$ \\
OC (N: 20) & - & $43.55 \pm 6.9^{\mathrm{A}}$ & $46.2 \pm 9.6^{\mathrm{A}}$ \\
Total & & $36.24 \pm 11.6^{\mathrm{A}}$ & $38.55 \pm 11.4^{\mathrm{A}}$ \\
Control (N: 40) & $40.9^{\mathrm{A}}$ & $42.28 \pm 6.25^{\mathrm{A}}$ & $39.2^{\mathrm{A}}$ \\
\hline
\end{tabular}

MDR: Multidrug resistant, RD: Recently diagnosed, OC: Old, Similar letters: No significant difference $(p>0.05)$ between means of rows

that the IL-17 AG genotype and AA genotype in SNP rs2275913 were increased the risk of TB. These results are different with reports from some other populations. In Chinese, there was significant difference in the distribution of the genotype frequencies for the IL-17A rs2275913 gene polymorphisms between the patients and controls [29]. In the community of northern Spain found significant differences in the distribution of alleles of the SNP rs2275913 between patients and control [18]. In addition, in southern Brazilian population, the A allele and GA genotype were associated with increased risk for TB development [32]. In Argentina population, Rolandelli et al. [27] found positively associated between AA genotypes from the IL-17 rs2275913 SNP and protection to active TB and finally, in North Indians, it was found that the frequency of genotype GA 86 (52.1\%) for SNP rs2275913 is higher than the frequency of both genotype GG 17 (10.3\%) and AA $43(41.1 \%)$ [19]. According to the results of this study, the frequency of A and $G$ alleles of IL-17 rs2275913 gene polymorphisms in Iraqi normal population were $50 \%$ for both alleles. A and G allele frequency in the healthy northern Spain population was about $37.22 \%$ and $62.78 \%$, respectively [18], which differ from that Chinese population in the percentage of allele $\mathrm{G}$ and A were $5.9 \%$ and $46.1 \%$, respectively [30].

The discrepancies in these results may be caused by differences in ethnicities, size of community sample, and study design, and also the control samples include individuals with latent TB status because the test of tuberculin was not done for each control sample. Some of the main characteristics, including drinking alcohol and smoking, were not available in this study, which caused a bias in the selection of the sample. The stage of infection cannot be determined directly from TB, which is more affected by IL-17, which supports the study by Zhang et al. [33]. Du et al. [28] showed that the selection of patients and control samples from one place, which may affect in limitation of the representation of other population. The small sample size has limited the statistical power of identifying the difference between groups [28,29]. Du et al. [28] showed the development of TB could be influenced by other genetic factors. As well as the weak effect of genetic polymorphism, other genes work together in an immunity pathway with some environmental factors and thus affect the development of TB $[30,31]$.

Few have studied the serum cytokine levels and its implications in the context of genotypes of TB patients [18, 27]. Such data on Iraqi population are lacking. Therefore, the present study was undertaken to determine the impact of cytokine genotypes on the production of investigated cytokines, PTB patients and controls were distributed according to their serum level in the three genotypes. Our finding suggests a lack of association of IL-17A rs2257913 polymorphisms in PTB patients or controls. The results agree with Ocejo-Vinyals et al. [18] who showed that no significant differences in IL-17A levels were found in PTB patients with different rs2275913 genotype in serum samples in northern Spain population. However, other data suggested that have associated between the AA genotype from the IL-17A rs2275913 SNP and serum level in Argentina population [27]. The lack of correlation between IL-17A production and IL-17A rs2275913 genotype might be due to the role of other adjacent functional IL-17A SNPs which could affect the expression of IL-17. Thus, IL-17A rs2275913 SNP would act as a surrogate marker for TB disease risk [18]. In conclusion, we suggest that the genotypes of rs2275913 polymorphisms were not associated with an increased risk of TB.

\section{AUTHOR'S CONTRIBUTION}

Nada Y. and Mohammed Q. done ELISA tests. Molecular study was carried out by Nawal M. and Samples collection from TB patients was done by Ahmed A. All authors contributed ideas and thought to the writing of this paper.

\section{CONFLICTS OF INTERESTS}

The authors declared that they have no conflicts of interest.

\section{REFERENCES}

1. Corral-Fernández NE, Cortes-García JD, Bruno RS, RomanoMoreno S, Medellín-Garibay SE, Magaña-Aquino M, et al. Analysis of transcription factors, microRNAs and cytokines involved in $\mathrm{T}$ lymphocyte differentiation in patients with tuberculosis after directly observed treatment short-course. Tuberculosis (Edinb) 2017;105:1-8.

2. Dheda K, Cox H, Esmail A, Wasserman S, Chang KC, Lange C, et al. Recent controversies about MDR and XDR-TB: Global implementation of the WHO shorter MDR-TB regimen and bedaquiline for all with MDR-TB? Respirology 2018;23:36-45.

3. Aliannejad R, Bahrmand A, Abtahi H, Seifi M, Safavi E, Abdolrahimi F, et al. Accuracy of a new rapid antigen detection test for pulmonary tuberculosis. Iran J Microbiol 2016;8:238-42.

4. Erie H, Kaboosi H, Javid N, Shirzad-Aski H, Taziki M, Kuchaksaraee MB, et al. The high prevalence of Mycobacterium tuberculosis Beijing strain at an early age and extra-pulmonary tuberculosis cases. Iran J Microbiol 2017;9:312-7.

5. Sajith MA, Thomas JJ, Kothia B, Chandrakar B, Pawar A, Bargaje MD. Cost of therapy incurred for tuberculosis patients receiving directly observed therapy (DOT). Int J Pharm Pharm Sci 2015;7:141-4.

6. Choi R, Kim K, Kim MJ, Kim SY, Kwon OJ, Jeon K, et al. Serum inflammatory profiles in pulmonary tuberculosis and their association with treatment response. J Proteomics 2016;149:23-30.

7. Narooie-Nejad M. Role of cytokine's functional single nucleotide polymorphisms in tuberculosis. Gene Cell Tissue 2017;4:e13337.

8. Lindenau JD, Guimarães LS, Friedrich DC, Hurtado AM, Hill KR, Salzano FM, et al. Cytokine gene polymorphisms are associated with susceptibility to tuberculosis in an Amerindian population. Int J Tuberc Lung Dis 2014;18:952-7.

9. Muller BL, Ramalho DM, Santos PF, Mesquita ED, Kritski AL, Oliveira MM, et al. Inflammatory and immunogenetic markers in correlation with pulmonary tuberculosis. J Bras Pneumol 2013;39:719-27.

10. Yang LJ, Gao W, Bai JY, Zhang XK, Han X, Sun YH, et al. Correlation between interleukin-17 gene polymorphism and gastric cancer susceptibility in Han Chinese population. Eur Rev Med Pharmacol Sci 2016;20:1271-82.

11. Iwakura Y, Ishigame H, Saijo S, Nakae S. Functional specialization of interleukin-17 family members. Immunity 2011;34:149-62.

12. Das $\mathrm{S}, \mathrm{Khader} \mathrm{S}$. Yin and yang of interleukin-17 in host immunity to infection. F1000Res 2017;6:741.

13. Liu S, Dakin LA, Xing L, Withka JM, Sahasrabudhe PV, Li W, et al. Binding site elucidation and structure guided design of macrocyclic IL17A antagonists. Sci Rep 2016;6:30859.

14. Miossec P. Update on interleukin-17: A role in the pathogenesis of inflammatory arthritis and implication for clinical practice. RMD Open 2017:3:e000284.

15. Teräsjärvi J, Hakanen A, Korppi M, Nuolivirta K, Gröndahl-YliHannuksela K, Mertsola J, et al. Rapid detection of functional gene polymorphisms of TLRs and IL-17 using high resolution melting analysis. Sci Rep 2017;7:41522.

16. Eskandari-Nasab E, Moghadampour M, Tahmasebi A. Meta-analysis of risk association between interleukin-17A and $\mathrm{F}$ gene polymorphisms and inflammatory diseases. J Interferon Cytokine Res 2017;37:165-74.

17. Bulat-Kardum LJ, Etokebe GE, Lederer P, Balen S, Dembic Z. Genetic polymorphisms in the toll-like receptor 10, interleukin (IL)17A and IL17F genes differently affect the risk for tuberculosis in Croatian population. Scand J Immunol 2015;82:63-9.

18. Ocejo-Vinyals JG, de Mateo EP, Hoz MÁ, Arroyo JL, Agüero R, Ausín F, et al. The IL-17 G-152A single nucleotide polymorphism is associated with pulmonary tuberculosis in Northern Spain. Cytokine 2013;64:58-61.

19. Abhimanyu, Bose M, Komal, Varma-Basil M. Lack of association 
between IL17A and IL17F polymorphisms and related serum levels in north Indians with tuberculosis. Gene 2013;529:195-8.

20. Hur YG, Kang YA, Jang SH, Hong JY, Kim A, Lee SA, et al. Adjunctive biomarkers for improving diagnosis of tuberculosis and monitoring therapeutic effects. J Infect 2015;70:346-55.

21. Chen YC, Chin $\mathrm{CH}$, Liu SF, Wu CC, Tsen CC, Wang YH, et al. Prognostic values of serum IP-10 and IL-17 in patients with pulmonary tuberculosis. Dis Markers 2011;31:101-10.

22. Liang YP, Chen Y, Xiao TY, Xia Q, Liu HC, Zhao XQ, et al. Applied multiplex allele specific PCR to detect second-line drug resistance among multidrug-resistant tuberculosis in china. Tuberculosis (Edinb) 2017;107:1-4.

23. Shaji J, Shaikh, M. Drug-resistant tuberculosis: Recent approach in polymer based nanomedicine. Int J Pharm Pharm Sci 2016:8:1-6.

24. Butov DO, Kuzhko MM, Makeeva NI, Butova TS, Stepanenko HL, Dudnyk AB, et al. Association of interleukins genes polymorphisms with multi-drug resistant tuberculosis in Ukrainian population. Pneumonol Alergol Pol 2016;84:168-73.

25. Basile JI, Kviatcovsky D, Romero MM, Balboa L, Monteserin J, Ritacco V, et al. Mycobacterium tuberculosis multi-drug-resistant strain $\mathrm{M}$ induces $\mathrm{IL}-17<$ sup $>+</$ sup $>$ IFN $\gamma<$ sup $>-</$ sup $>\operatorname{CD} 4<$ sup $>+</$ sup $>\mathrm{T}$ cell expansion through an IL-23 and TGF- $\beta$-dependent mechanism in patients with MDR-TB tuberculosis. Clin Exp Immunol 2017;187:160-73.

26. Białecka M, Ostasz R, Kurzawski M, Klimowicz A, Fabiańczyk $\mathrm{H}$, Bojko P, et al. IL17A and IL17F gene polymorphism association with psoriasis risk and response to treatment in a polish population.
Dermatology 2016:232:592-6

27. Rolandelli A, Hernández Del Pino RE, Pellegrini JM, Tateosian NL, Amiano NO, de la Barrera S, et al. The IL-17A rs2275913 single nucleotide polymorphism is associated with protection to tuberculosis but related to higher disease severity in Argentina. Sci Rep $2017 ; 7: 40666$

28. Du J, Han J, Li X, Zhang Y, Li H, Yang S, et al. StIL-17 gene polymorphisms in the development of pulmonary tuberculosis. Int $\mathrm{J}$ Clin Exp Pathol 2015;8:3225-9.

29. Shi GC, Zhang LG. Influence of interleukin-17 gene polymorphisms on the development of pulmonary tuberculosis. Genet Mol Res 2015; 14:8526-31.

30. Wang Y, Xu L, Zhang L, He Y, Yang C, Huang A. Construction the recombinant $\mathrm{BCG}$ targeting delivering IPRI into macrophages: A new strategy of vaccine against tuberculosis. Afr J Microbiol Res 2013;7:533-40.

31. Mansouri F, Heydarzadeh R, Yousefi S. The association of interferon-gamma, interleukin-4 and interleukin-17 single-nucleotide polymorphisms with susceptibility to tuberculosis. APMIS 2018:126:227-33

32. Milano M, Moraes MO, Rodenbusch R, Carvalho CX, Delcroix M, Mousquer G, et al. Single nucleotide polymorphisms in IL17A and IL6 are associated with decreased risk for pulmonary tuberculosis in southern Brazilian population. PLoS One 2016;11:e147814.

33. Zhang J, Zheng L, Zhu D, An H, Yang Y, Liang Y, et al. Polymorphisms in the interleukin 18 receptor 1 gene and tuberculosis susceptibility among Chinese. PLoS One 2014;9:e110734. 